\title{
On Control of Whole Temperature Profile in an Autothermal Tube-Cooled Fixed Bed Catalytic Reactor
}

\author{
M Chew-Hernandez, W.E. Jones and J.A. Wilson ${ }^{*}$ \\ School of Chemical, Environmental and Mining Engineering \\ University of Nottingham. University Park. Nottingham. NG7 2RD, UK
}

\begin{abstract}
In this work the Minimum Error Profile (MEP) algorithm (Wahl et al., 2002) is applied to control of temperature profile in an Autothermal Reactor with Internal Countercurrent Heat Exchange (ARICHE). Measurements of catalyst temperature at points along the reactor length form the basis on which the rest of the reactor states are estimated through an Extended Kalman filter. These state estimates are used to calculate the control actions necessary to drive the reactor optimally to the set point given by the MEP calculation. When subjected to sinusoidal variations in inlet compositions a LQR using the MEP as set point shows a superior performance when compared with controlling to a fixed steady state profile. In the case study presented, which has the potential for reaction run-away, this translates into safer control of the system.
\end{abstract}

Keywords: temperature profile control, fixed bed catalytic reactor control, tube-cooled reactor control; plug flow reactor control; reaction recycle-loop control

\section{References}

Wahl T.,Jones W.E., and Wilson J.A., 2002, A Scheme for whole temperature profile control in distributed parameter systems, Proc. ESCAPE-12, pp 577-582

\footnotetext{
* Author to whom correspondence should be adressed : j.a.wilson@nottingham.ac.uk
} 